\title{
Implementasi Metode Analytic Hierarchy Process dalam Pemilihan Radar Udara 3D
}

\author{
Arifin Setiawan ${ }^{1 *}$, Wiedo Ananto ${ }^{2)}$, Totok Soehartanto ${ }^{3)}$ \\ 1,2 Sekolah Staf Dan Komando Angkatan Laut, ${ }^{3}$ Institut Teknologi Sepuluh Nopember \\ 1 arifin_setiawan@tnial.mil.id, ${ }^{2}$ wiedo_ananto@tnial.mil.id, ${ }^{3}$ totokstf@yahoo.com
}

DOI: https://doi.org/10.21107/rekayasa.v13i1.6778

\begin{abstract}
ABSTRAK
Dalam kehidupan sehari-hari, seseorang senantiasa dihadapkan pada pilihan dari berbagai pilihan, terkait proses pengambilan keputusan diperlukan penentuan prioritas dan uji konsistensi terhadap pilihan-pilihan yang telah dilakukan. Dalam situasi yang kompleks, pengambilan keputusan tidak dipengaruhi oleh satu faktor saja melainkan multifaktor dan mencakup berbagai jenjang maupun kepentingan. Pengambilan keputusan oleh para pimpinan seringkali dihadapkan pada permasalahan yang sulit karena beragamnya kriteria pengambilan keputusan, bobot pertimbangan dan pilihan alternatif. Penelitian ini menggunakan metode kualitatif dan kuantitatif dengan metode pengambilan keputusan secara Analytic Hierarchy Process (AHP). Metode Analytical Hierrchy Process (AHP) digunakan untuk mencari rangking atau urutan prioritas dari berbagai alternatif dalam pemecahan suatu permasalahan. Metode ini membantu dalam memecahkan persoalan yang kompleks dengan menstruktur suatu hirarki kriteria, pihak yang berkepentingan, dan hasil dengan menarik berbagai pertimbangan guna mengembangkan bobot atau prioritas. KRI sebagai bagian dari alutsista TNI AL, seluruhnya menggunakan Radar (Radio Detection and Ranging) yang berfungsi sebagai peralatan deteksi sasaran, baik sasaran permukaan maupun sasaran udara. Radar bekerja dengan memancarkan dan menerima kembali gelombang elektromagnetik untuk selanjutnya diproses menjadi sinyal video yang kemudian ditampilkan sebagai echo pada layar display. (Skolnik, 2001) Penelitian ini didasari oleh permasalahan belum optimalnya cara kerja Radar 3D pada KRI Kelas Bung Tomo (MRLF-Multi Role Light Fregate). Permasalahan ini berdampak pada kemampuan operasional KRI, sehingga diperlukan kajian lebih lanjut dengan cara membandingkan karakteristik statik, keandalan dan kompleksitas Radar Udara 3D Smart S MK2, MW-08 dan AWS-09. Hasil akhir adalah Radar Udara 3D Smart S MK2 merupakan Radar Udara terbaik untuk KRI Kelas Bung Tomo karena memiliki keunggulan dalam jarak jangkau dan sensitivitas.
\end{abstract}

Kata Kunci : Eigen Value, Consistenci Index, Random Index, Consistenci Rasio.

\section{PENDAHULUAN}

Metode Analytical Hierrchy Process (AHP) merupakan suatu metode pengambilan keputusan yang dikembangkan oleh Thomas L. Saaty dari Wharton Business School di awal tahun 1970. Model pengambilan keputusan ini menguraikan masalah multi kriteria atau multi faktor yang kompleks menjadi suatu hirarki[Djoko Wijono, 2015]. Hirarki didefinisikan sebagai suatu representasi dari sebuah permasalahan yang kompleks dalam struktur multi level dimana level pertama adalah tujuan, yang diikuti level kriteria, sub kriteria dan seterusnya hingga level terakhir alternatif. AHP memberikan nilai bobot relatif dari suatu kriteria majemuk atau alternatif majemuk secara intuitif yaitu dengan melakukan perbandingan berpasangan dengan menggunakan skala perbandingan berpasangan yang ditentukan oleh Saaty. AHP juga menguji konsistensi penilaian, konsistensi yang diharapkan adalah yang mendekati sempurna agar menghasilkan keputusan yang valid. Rasio konsistensi yang diharapkan adalah kurang dari atau sama dengan $10 \%$.

Perubahan teknologi yang sangat pesat sebagai

\section{Article History:}

Received: September, 12 $2^{\text {th }}$ 2019; Accepted: January, $12^{\text {th }} 2020$ ISSN: 2502-5325 (Online) Terakreditasi Peringkat 3 oleh Kementerian Riset, Teknologi dan Pendidikan Tinggi (ARJUNA), berdasarkan Keputusan Direktur Jenderal Penguatan Riset dan Pengembangan No: 23/E/KPT/2019 tanggal 8 Agustus 2019 imbas dari revolusi industri 4.0, menuntut dunia militer untuk meng-upgrade kemampuan persenjataan kapal perangnya agar berbasis pada penggunaan teknologi big data dan artificial intelligence. Oleh karena itu, Radar Udara 3D yang terpasang di KRI kelas Bung Tomo yang dimiliki TNI AL saat ini telah mengadopsi teknologi 4.0. Namun Radar 3D tersebut memiliki kekurangan yang disebabkan oleh suku cadang yang sudah obsolete, Radar yang tidak support loT dan assembly serta transmitter unit failure. Metode penelitian menggunakan Analytic Hierarchy Process (AHP) dengan didukung data parametrik dan non parametrik terhadap Radar Udara 3D Smart S MK2, MW-08 dan AWS-09. Sehingga diperoleh hasil akhir yaitu jenis Radar Udara 3D terbaik untuk KRI kelas Bung Tomo yang memiliki keunggulan dalam jarak jangkau dan sensitivitas.

Analytic Hierarchy Process (AHP) membantu pengambilan keputusan dalam pemilihan Radar Udara 3D KRI Kelas Bung Tomo terhadap pemilihan Radar Udara 3D yang terbaik berdasarkan tiga pilihan Radar Udara 3D milik KRI terbaru TNI AL sehingga dapat diketahui potensi pengembangannya agar dapat support dengan Internet of Thinks (IoT) untuk menunjang era revolusi industry 4.0.

\section{Cite this as:}

Setiawan, A., Wiedo Ananto, W., \& Soehartanto, T. (2020). SImplementasi Metode Analytic Hierarchy Process dalam Pemilihan Radar Udara 3D. Rekayasa, 13(1), 49-54. doi: https://doi. org/10.21107/rekayasa.v13i1.6778 
50 | Fitria, L., dkk, Status Mutu Air pada Lahan Gambut di Sungai Putat ..

\section{METODE PENELITIAN}

\section{Metode Kualitatif}

Metode analisis kualitatif adalah dengan melakukan wawancara secara mendalam kepada para pejabat TNI AL korps elektronika yang ahli dibidang perbaikan dan perawatan Radar Udara 3D, untuk menggali kriteria-kriteria, subkriteria-subkriteria dan alternatif-alternatif pemilihan Radar Udara 3D. Berdasarkan hasil wawancara, pengambilan keputusan pemilihan Radar Udara 3D sebagai berikut :

Tabel 1. Kriteria dan Sub Kriteria Sebagai Dalam Pemilihan Radar

\begin{tabular}{|c|c|c|}
\hline KRITERIA & $\begin{array}{l}\text { SUB- } \\
\text { KRITERIA }\end{array}$ & PENJELASAN \\
\hline \multirow[t]{3}{*}{$\begin{array}{l}\text { Karak- } \\
\text { teristik } \\
\text { Statik }\end{array}$} & $\begin{array}{l}\text { Jarak Jang- } \\
\text { kau }\end{array}$ & $\begin{array}{l}\text { Jarak maksimum / minimum } \\
\text { yang dapat diditangkap oleh } \\
\text { Radar. }\end{array}$ \\
\hline & Sensitivitas & $\begin{array}{l}\text { Perubahan output instrumen yang } \\
\text { terjadi ketika kualitas pengukuran } \\
\text { berubah. }\end{array}$ \\
\hline & Akurasi & $\begin{array}{l}\text { Ketepatan radar dalam memberi- } \\
\text { kan hasil pengukuran. }\end{array}$ \\
\hline \multirow[t]{3}{*}{$\begin{array}{l}\text { Keanda- } \\
\text { lan }\end{array}$} & Usia Pakai & $\begin{array}{l}\text { Lama waktu suatu Radar dapat } \\
\text { dipakai dan masih menguntung- } \\
\text { kan secara ekonomi }\end{array}$ \\
\hline & $\begin{array}{l}\text { Kemam- } \\
\text { puan }\end{array}$ & $\begin{array}{l}\text { Kapasitas sebuah Radar dalam } \\
\text { melakukan peran dan fungsinya } \\
\text { untuk mendeteksi target. }\end{array}$ \\
\hline & $\begin{array}{l}\text { Mainte- } \\
\text { nance }\end{array}$ & $\begin{array}{l}\text { Tindakan untuk menjaga atau } \\
\text { memperbaiki suatu Radar menja- } \\
\text { di kondisi semula }\end{array}$ \\
\hline \multirow[t]{3}{*}{$\begin{array}{l}\text { Kom- } \\
\text { pleksitas }\end{array}$} & $\begin{array}{l}\text { Kemuda- } \\
\text { han Opera- } \\
\text { sional }\end{array}$ & $\begin{array}{l}\text { Kemudahan dalam tingkat pen- } \\
\text { goperasian Radar. }\end{array}$ \\
\hline & Kompatibel & $\begin{array}{l}\text { Kemudahan dalam pengemba- } \\
\text { ngan dan pengintegrasian } \\
\text { dengan sistem senjata atau } \\
\text { sistem kontrol yang ada. (hard- } \\
\text { ware) }\end{array}$ \\
\hline & $\begin{array}{l}\text { Kemu- } \\
\text { dahan } \\
\text { Upgrading }\end{array}$ & $\begin{array}{l}\text { Kemudahan dalam mengupgrade } \\
\text { Radar sesuai dengan perkem- } \\
\text { bangan teknologi. (software) }\end{array}$ \\
\hline
\end{tabular}

\section{Metode Kuantitatif}

Peneliti melakukan analisis kuantitatif dalam studi kasus ini dengan menggunakan metode Analytic Hierarchy Process (AHP) dalam pemilihan Radar Udara 3D . Langkah dan prosedur penggunaan metode AHP sebagai berikut:

- Mendefinisikan masalah dan menentukan solusi yang diinginkan.

- Membuat struktur hirarki yang diawali dengan tujuan umum, dilanjutkan dengan kriteriakriteria dan alternaif-alternatif pilihan yang ingin di ranking.

- Membentuk matriks perbandingan berpasangan (pairwise comparison) yang menggambarkan kontribusi relatif atau pengaruh setiap elemen terhadap masing- masing tujuan atau kriteria yang setingkat diatasnya. Perbandingan dilakukan berdasarkan pilihan atau judge- ment dari pembuat keputusan dengan menilai tingkat tingkat kepentingan suatu elemen dibandingkan elemen lainnya.

- Menormalkan data yaitu dengan membagi nilai dari setiap elemen di dalam matriks yang berpasangan dengan nilai total dari setiap kolom.

- Menghitung nilai eigen vector dan menguji konsistensinya, jika tidak konsisten maka pengambilan data (preferensi) perlu diulangi. Nilai eigen vector yang dimaksud adalah nilai eigen vector maksimum yang diperoleh dengan manual.

- Mengulangi langkah 3, 4, dan 5 untuk seluruh tingkat hirarki.

- Menghitung eigen vector dari setiap matriks perbandingan berpasangan. Nilai eigen vector merupakan bobot setiap elemen. Langkah ini untuk mensintesis pilihan dalam penentuan prioritas elemen-elemen pada tingkat hirarki terendah sampai pencapaian tujuan.

- Menguji konsistensi hirarki. Jika tidak memenuhi dengan $C R<0,10$; maka penilaian harus diulang kembali.

\section{HASIL DAN PEMBAHASAN}

Berdasarkan kriteria, subkriteria dan alternatif Radar Udara 3D yang sudah ditetapkan, maka pemilihan Radar Udara 3D menggunakan Metode Analytical Hierarchy Process (AHP) prosesnya sebagai berikut:

- Menetapkan permasalahan, kriteria, dan alternatif pilihan.

- Membentuk matrik pairwise comparison kriteria.

- Menentukan rangking kriteria dalam bentuk vector prioritas (disebut juga eigen vector ternormalisasi).

- Menentukan rangking kriteria dalam bentuk vector prioritas (disebut juga eigen vector ternormalisasi).

- Menentukan ranking dari alternatif lokasi dengan cara menghitung eigen vector untuk tiap kirteria.

\section{Menetapkan Permasalahan, Kriteria, dan Alter- natif Pilihan}

Langkah-langkah dalam proses menetapkan permasalahan, kriteria, dan alternatif pilihan adalah:

- Permasalahan: Menentukan pilihan Radar Udara 3D yang tepat.

- Pemilihan Radar Udara 3D terbaik yang harus memenuhi kriteria:

a. Kriteria Karakteristik Statik: Jarak Jangkau, Sensitivitas dan Akurasi.

b. Kriteria Keandalan: Usia Pakai, Kemampuan dan Maintenance. 
c. Kriteria Kompleksitas: Kemudahan Operasional, Kompleksitas dan Kemudahan Upgrading.

\section{Membentuk Matrik Pairwise Comparison Kriteria}

Terlebih dahulu melakukan penilaian perbandingan berpasangan antar kriteria. Perbandingan antar kriteria didasarkan pada kinerja Radar Udara 3D. Keputusan hasil perbandingan berpasangan antar kriteria sebagai berikut:

- Kriteria Karakteristik Statik adalah 2.47 kali lebih penting dari Kriteria Keandalan.

- Kriteria Karakteristik Statik adalah 3.91 kali lebih penting dari Kriteria Kompleksitas.

- Kriteria Keandalan adalah 3.98 kali lebih penting dari Kriteria Kompleksitas.

Hasil perbandingan berpasangan antar kriteria yang disusun dalam bentuk matrik Pairwise Comparison sebagai berikut:

Tabel 2. Matriks Pairwise Comparation Pairwise comparation matrix

\begin{tabular}{cccc}
\hline Kriteria & K. Statik & Keandalan & Maintenance \\
\hline K. Statik & 1 & 2.47 & 3.91 \\
Keandalan & $1 / 2.47$ & 1 & 3.98 \\
Maintenance & $1 / 3.91$ & $1 / 3.98$ & 1 \\
\hline
\end{tabular}

(Sumber : Hasil olah data Secara Excel)

Menentukan rangking kriteria dalam bentuk vector prioritas (disebut juga eigen vector ternomalisasi)

Langkah-langkah penyusunan sebagai berikut :

- Ubah matriks Pairwise Comparison ke bentuk desimal dan jumlahkan tiap kolom tersebut.

- Hitung Eigen Vector normalisasi dengan cara jumlahkan tiap baris kemudian dibagi dengan jumlah kriteria dalam permasalahan ini adalah 3

- Menghitung nilai principal eigen value $(\lambda$ max), consistency index $(\mathrm{Cl})$ dan consistency rasio $(\mathrm{CR})$ untuk mengetahui apakah penilaian perbandingan kriteria bersifat konsisten.

Tabel 3. Eigen Vector Normalisasi

Pairwise comparation matrix

\begin{tabular}{|c|c|c|c|c|}
\hline Kriteria & $\begin{array}{c}\text { K. } \\
\text { Statik }\end{array}$ & $\begin{array}{l}\text { Kean- } \\
\text { dalan }\end{array}$ & $\begin{array}{c}\text { Main- } \\
\text { te- } \\
\text { nance }\end{array}$ & $\begin{array}{l}\text { E. V. Normal- } \\
\text { isasi }\end{array}$ \\
\hline K. Statik & 1,00 & 2,47 & 3,91 & 0,5751742 \\
\hline Keandalan & 0,41 & 1,00 & 3,98 & 0,3166436 \\
\hline $\begin{array}{l}\text { Kompleksi- } \\
\text { tas }\end{array}$ & 0,26 & 0,25 & 1,00 & 0,1081821 \\
\hline Jumlah & 1,67 & 3,72 & 8,89 & \\
\hline \multicolumn{4}{|c|}{ Principal Eigen Value ( $\lambda \max )$} & 3,09519 \\
\hline \multicolumn{4}{|c|}{ Consistency Index (Cl) } & 0,0476 \\
\hline \multicolumn{4}{|c|}{ Consistency Ratio (CR) } & 0,08206 \\
\hline
\end{tabular}

(Sumber : Hasil olah data Secara Excel)
Keterangan:

- Jumlah merupakan penjumlahan dari semua angka yang ada pada baris diatasnya dalam satu kolom.

Eigen Vector merupakan hasil penjumlahan dari semua sel disebelah Kirinya (pada baris yang sama) setelah terlebih dahulu dibagi dengan baris jumlah yang ada dibawahnya, kemudian hasil penjumlahan tersebut dibagi dengan angka 3.

- Angka 3 diperoleh dari jumlah kriteria yaitu karakteristik statik, keandalan, dan kompleksitas.
1) Eigen vector $=0,575174$ diperoleh dari perhitungan $(1,00 / 1,660613+$ $2,47 / 3,7212563+3,91 / 8,89) * 1 / 3$
2) Eigen vector $=0,316644$ diperoleh dari perhitungan $(0,404858 / 1,660613+$ $1,00 / 3,7212563+3,98 / 8,89) * 1 / 3$
3) Eigen vector $=0,108182$ diperoleh dari perhitungan $(0,255754 / 1,660613+$ $3,7212563 / 6,33333+1,00 / 8,89) * 1 / 3$

- Eigen Vector menunjukan bobot dari masing-masing kriteria, jadi dalam hal ini Karakteristik Statik merupakan bobot tertinggi / terpenting dalam pemilihan Radar Udara 3D, disusul Kompleksitas dan bobot terendah adalah Keandalan.

- Setelah mendapatkan bobot untuk setiap kriteria (yang ada pada kolom Eigen Vector), maka selanjutnya mengecek apakah bobot yang dibuat konsisten atau tidak. Untuk hal ini, yang pertama yang dilakukan adalah menghitung Principal Eigen Value $(\lambda \max )$ matrix.

- Principal Eigen Value $(\lambda \max )$ matrix perhitungannya dengan cara menjumlahkan hasil perkalian antara jumlah dan priority vector.

- Principal Eigen Value $(\lambda \max )=(1,660613 \times$ $0,575174)+(3,7212563 \times 0,0,316644)+(8,89 x$ $0,108182)=3,09519$

Tabel 4 Daftar Random Index (RI)

\begin{tabular}{cc}
\hline Ukuran Matriks & Nilai RI \\
\hline $1-2$ & 0,00 \\
3 & 0,58 \\
4 & 0,90 \\
5 & 1,12 \\
6 & 1,24 \\
7 & 1,32 \\
8 & 1,41 \\
9 & 1,45 \\
10 & 1,49 \\
11 & 1,51 \\
12 & 1,58 \\
\hline
\end{tabular}


52 | Fitria, L., dkk, Status Mutu Air pada Lahan Gambut di Sungai Putat ..

- Menghitung Consistency Index $(\mathrm{Cl})$ dengan rumus: $\mathrm{Cl}=(\lambda \max -\mathrm{n}) /(\mathrm{n}-1)$, untuk $\mathrm{n}=3$

- $\mathrm{Cl}=(3,09519-3) /(3-1)=0,0476, \mathrm{Cl}$ mendekati nol berarti pembobotan yang dilakukan konsisten.

- Menghitung Consistency Ratio (CR) diperoleh dengan rumus $\mathrm{CR}=\mathrm{Cl} / \mathrm{RI}$, nilai $\mathrm{RI}$ (Random Index) bergantung pada jumlah kriteria seperti pada tabel 4.

Keterangan : Apabila nilai $\mathrm{CR} \leq 0.10$ maka data konsisten atau dapat ditoleransi tetapi bila $C R \geq$ 0.10 maka data tidak konsisten dan perlu dilakukan revisi. Apabila nilai $C R=0$, dapat dikatakan "perfectly consistent".

Jadi untuk $\mathrm{n}=3$ dan $\mathrm{RI}=0,58$

maka $\mathrm{CR}=\mathrm{Cl} / \mathrm{RI}=0,0476 / 0,58=0,08206$

Jika hasil perhitungan $C R$ lebih kecil atau sama dengan 0,10 , ketidakkonsistenan masih bisa diterima, sebaliknya jika lebih besar dari 0,10 tidak bisa diterima.

Tabel 5. Matriks Pairwise Comparation Kriteria Karakteristik Statik

Pairwise comparation matrix

\begin{tabular}{|c|c|c|c|c|}
\hline Kriteria & $\begin{array}{c}\text { Jarak } \\
\text { Jang- } \\
\text { kau }\end{array}$ & $\begin{array}{l}\text { Sensi- } \\
\text { tivitas }\end{array}$ & Akurasi & $\begin{array}{c}\text { Eigen Vector Nor- } \\
\text { malisasi }\end{array}$ \\
\hline $\begin{array}{c}\text { Jarak } \\
\text { jangkau }\end{array}$ & 1,00 & 1,13 & 2,97 & 0,4434571 \\
\hline $\begin{array}{l}\text { Sensitivi- } \\
\text { tas }\end{array}$ & 0,89 & 1,00 & 3,12 & 0,4155265 \\
\hline Akurasi & 0,34 & 0,32 & 1,00 & 0,1410164 \\
\hline Jumlah & 2,23 & 2,45 & 7,09 & 1,000000000 \\
\hline \multicolumn{4}{|c|}{ Principal Eigen Value ( $\lambda$ max) } & 3,003268 \\
\hline \multicolumn{4}{|c|}{ Consistency Index (Cl) } & 0,001634 \\
\hline \multicolumn{4}{|c|}{ Consistency Ratio (CR) } & 0,00282 \\
\hline
\end{tabular}

Tabel 6. Matriks Pairwise Comparation Kriteria Keandalan

Pairwise comparation matrix

\begin{tabular}{|c|c|c|c|c|}
\hline Kriteria & $\begin{array}{l}\text { Opera- } \\
\text { sional }\end{array}$ & $\begin{array}{c}\text { Kompa- } \\
\text { tible }\end{array}$ & $\begin{array}{l}\text { Upgrad- } \\
\text { ing }\end{array}$ & $\begin{array}{l}\text { Eigen Vector } \\
\text { Normalisasi }\end{array}$ \\
\hline $\begin{array}{l}\text { Mudah } \\
\text { Opera- } \\
\text { sional }\end{array}$ & 1,00 & 2,81 & 3,12 & 0,5888735 \\
\hline $\begin{array}{l}\text { Kompat- } \\
\text { ible }\end{array}$ & 0,36 & 1,00 & 2,63 & 0,2745043 \\
\hline $\begin{array}{c}\text { Mudah } \\
\text { Upgrading }\end{array}$ & 0,32 & 0,38 & 1,00 & 0,1366222 \\
\hline Jumlah & 1,68 & 4,19 & 6,75 & 1,000000000 \\
\hline \multicolumn{4}{|c|}{ Principal Eigen Value ( $\lambda$ max) } & 3,083195 \\
\hline \multicolumn{4}{|c|}{ Consistency Index (Cl) } & 0,0415975 \\
\hline \multicolumn{4}{|c|}{ Consistency Ratio (CR) } & 0,07172 \\
\hline
\end{tabular}

(Sumber:Hasil olah data Secara Excel)
Menentukan ranking dari Altenatif dengan cara menghitung eigen vector untuk tiap kriteria.

1. Memberikan penilaian bobot kriteria Karakteristik Statik :
a. Jarak Jangkau adalah 1,13 kali lebih penting dari Sensitivitas
b. Jarak Jangkau adalah 2,97 kali lebih penting Akurasi
c. Sensitivitas adalah 3,12 kali lebih penting Akurasi

Arti dari tabel 5 di atas adalah dari ketiga faktor karakteristik statik Radar Udara 3D, yang paling berpengaruh adalah Jarak Jangkau dengan skor 0,443, disusul Sensitivitas dengan skor 0,416, dan terakhir Akurasi dengan skor 0,141.

Nilai $\mathrm{Cl}$ adalah 0,001634, yang berarti $\mathrm{Cl}$ mendekati nol berarti pembobotan yang dilakukan konsisten. Sedangkan nilai $C R=0,00282$ lebih kecil dari 0,10 maka kekonsistenan penilaian kriteria masih bisa diterima.

1. Memberikan penilaian bobot Kriteria KeandaIan :
a. Usia Pakai adalah 2,81 kali lebih penting dari Kemampuan.
b. Usia Pakai adalah 3,12 kali lebih penting dari Maintenance.
c. Kemampuan adalah 2,63 kali lebih pent- ing dari Maintenance.

Arti dari tabel 6 di atas adalah dari ketiga faktor Keandalan Radar Udara 3D, yang paling berpengaruh adalah usia pakai dengan skor 0,589, disusul Kemampuan dengan skor 0,275, dan terakhir maintenancel dengan skor 0,136.

Nilai $\mathrm{Cl}$ adalah 0,0415975, yang berarti $\mathrm{Cl}$ mendekati nol berarti pembobotan yang dilakukan konsisten. Sedangkan nilai $C R=0,07172$ lebih kecil dari 0,10 maka kekonsistenan penilaian kriteria masih bisa diterima.

Tabel 7. Matriks Pairwise Comparation Kriteria Kompleksitas

Pairwise comparation matrix

\begin{tabular}{|c|c|c|c|c|}
\hline Kriteria & $\begin{array}{l}\text { Opera- } \\
\text { sional }\end{array}$ & $\begin{array}{l}\text { Kompat- } \\
\text { ibe }\end{array}$ & $\begin{array}{l}\text { Upgrad- } \\
\text { ing }\end{array}$ & $\begin{array}{l}\text { Eigen Vector } \\
\text { Normalisasi }\end{array}$ \\
\hline $\begin{array}{l}\text { Mudah } \\
\text { Opera- } \\
\text { sional }\end{array}$ & 1,00 & 3,56 & 2,79 & 0,6117649 \\
\hline Kompatibe & 0,28 & 1,00 & 1,13 & 0,1929853 \\
\hline $\begin{array}{c}\text { Mudah } \\
\text { Upgrading }\end{array}$ & 0,36 & 0,89 & 1,00 & 0,1952499 \\
\hline Jumlah & 1,63932 & 5,46090 & 4,9 & 1,000000000 \\
\hline \multicolumn{4}{|c|}{ Principal Eigen Value ( $\lambda \max )$} & 3,013477 \\
\hline \multicolumn{4}{|c|}{ Consistency Index (Cl) } & 0,006739 \\
\hline \multicolumn{4}{|c|}{ Consistency Ratio (CR) } & 0,01162 \\
\hline
\end{tabular}

(Sumber: Hasil olah data Secara Excel) 
2. Memberikan penilaian bobot kriteria Kompleksitas :

a. Kemudahan Operasional adalah 3.56 kali lebih penting dari Kompatibel

b. Kemudahan Operasional adalah 2.79 kali lebih penting dari Kemudahan Upgrading

c. Kompatibel adalah 1.13 kali lebih penting dari Kemudahan Upgrading.

Arti dari tabel di atas adalah dari ketiga Kompleksitas Radar Udara 3D, yang paling berpengaruh adalah Kemudahan Operasional dengan skor 0, 612, disusul Kemampuan Upgrading dengan skor 0,195, dan terakhir Kompatibel dengan skor 0, 193.

Nilai $\mathrm{Cl}$ adalah 0,006739, yang berarti $\mathrm{Cl}$ mendekati nol berarti pembobotan yang dilakukan konsisten. Sedangkan nilai $C R=0,01162$ lebih kecil dari 0,10 maka kekonsistenan penilaian kriteria masih bisa diterima.

\section{Menghitung Total Skor Kriteria untuk Ketiga Alternatif}

Semua hasil penilaian bobot ketiga kriteria tersebut disusun dalam bentuk tabel yang disebut Overall composite weight.

Tabel 8 Overall Composite Weight

\begin{tabular}{|c|c|c|c|c|}
\hline $\begin{array}{l}\text { Overall } \\
\text { composite } \\
\text { weight }\end{array}$ & Weight & $\begin{array}{c}\text { SMART S } \\
\text { MK2 }\end{array}$ & MW-08 & AWS-09 \\
\hline $\begin{array}{c}\text { Jarak Jang- } \\
\text { kau }\end{array}$ & 0.355 & 0.410744 & 0.287128 & 0.302129 \\
\hline Sensitivitas & 0.334 & 0.675732 & 0.144105 & 0.180163 \\
\hline Akurasi & 0.113 & 0.480256 & 0.375019 & 0.144725 \\
\hline Usia Pakai & 0.028 & 0.615041 & 0.271750 & 0.113209 \\
\hline $\begin{array}{l}\text { Kemam- } \\
\text { puan }\end{array}$ & 0.013 & 0.657066 & 0.251668 & 0.091266 \\
\hline $\begin{array}{l}\text { Mainte- } \\
\text { nance }\end{array}$ & 0.007 & 0.619966 & 0.231902 & 0.148132 \\
\hline $\begin{array}{l}\text { Mdh Oper- } \\
\text { asional }\end{array}$ & 0.092 & 0.630479 & 0.260836 & 0.108684 \\
\hline Kompatibel & 0.029 & 0.618746 & 0.27054 & 0.110714 \\
\hline $\begin{array}{l}\text { Mdh Up- } \\
\text { grading }\end{array}$ & 0.029 & 0.606468 & 0.28256 & 0.110972 \\
\hline $\begin{array}{c}\text { Composite } \\
\text { Weight }\end{array}$ & & 0.5494155 & 0.2449794 & 0.2056052 \\
\hline
\end{tabular}

(Sumber : Hasil Olah Data Menggunakan Expert Choice 11)

Keterangan:

1. Weight diambil dari kolom Eigen Vector dalam matrix kriteria.

2. Kolom (SMART S, MW-08, AWS-09) diambil dari kolom Eigen Vector ketiga matrix

3. Sub-kriteria terdiri dari Jarak Jangkau, Sensitivitas, Akurasi, Life Time, Kemudahan Operasional, Kompatibel, Kemudahan Upgrading.

4. Composite weight diperoleh dari hasil jumlah perkalian kolom tiap sub-kriteria dengan Weight. a. SMART S MK2 $=(0,4107437 \times 0,355)+$ $(0,6757319 \times 0,334)+(0,4802559 \times 0,113)$ $+(0,6150407 \times 0,028)+(0,6570663$ $\times 0,013)+(0,6199663 \times 0,007)+$ $(0,6304794 \times 0,092)+(0,6187461 \times 0,029)$

$+(0,6064678 \times 0,029)=0.5494155$

b. $\mathrm{MW}-08=(0,2871277 \times 0,355)+$ $(0,1441049 \times 0,334)+(0,3750190 \times 0,113)$ $+(0,2717502 \times 0,028)+(0,2516679$ $\times 0,013)+(0,2319016 \times 0,007)+$ $(0,2608362 \times 0,092)+(0,2705403 \times 0,029)$ $+(0,2825599 \times 0,029)=0.2449794$

c. $\quad$ AWS $-09=(0,3021286 \times 0,355)+$ $(0,1801632 \times 0,334)+(0,1447252 \times 0,113)$ $+(0,1132091 \times 0,028)+(0,0912658$ $\times 0,013)+(0,1481320 \times 0,007)+$ $(0,1086844 \times 0,092)+(0,1107136 \times 0,029)$

$+(0,1109723 \times 0,029)=0.2056052$

Dari tabel diatas dapat disimpulkan bahwa Radar SMART S MK2 mempunyai skor paling tinggi yaitu 0,54941, kemudian Radar MW-08 dengan skor 0,24497 dan paling bawah Radar AWS-09 0,20560. Sehingga Radar Udara 3D yang paling baik dan dipilih adalah SMART S MK2.

\section{KESIMPULAN DAN SARAN}

Kesimpulan yang dapat diambil adalah :

1. Metode Analytic Hierarchy Process (AHP) merupakan salah satu model pengambilan keputusan multikriteria yang dapat membantu kerangka berpikir manusia dimana faktor logi$\mathrm{ka}$, pengalaman, pengetahuan dan pendapat dioptimalisasikan kedalam suatu proses sistematis.

2. Metode Analytic Hierarchy Process (AHP) dapat membantu pengambilan keputusan dalam pemilihan Radar Udara 3D untuk KRI kelas Bung Tomo.

3. Berdasarkan proses analisa, pembahasan dan hasil pembobotan dari seluruh alternatif Radar Udara 3D didapat urutan rangking alternatif sebagai berikut :

a. Radar Udara 3D Smart S MK2 sebesar 0,54941 atau $54,9 \%$.

b. Radar Udara 3D MW-08 sebesar 0,24497 atau $24,5 \%$

c. Radar Udar 3D AWS-09 sebesar 0,20560 atau $20,6 \%$

\section{DAFTAR PUSTAKA}

Skolnik, (2001), Radar Handbook, "An Introduction to Radar".

Jenn David,(2016) Radar Fundamental, Department of Electrical \& Computer Engineering, NPS. 
54 | Fitria, L., dkk, Status Mutu Air pada Lahan Gambut di Sungai Putat ..

Talitha Tita, (2015), Penggunaan Metode Analytical Hierarchy Process (AHP) untuk Pemilihan Asisten Praktikum, SEMANTIK.

Saaty, Thomas L., (2013), AHP Untuk Pengambilan Keputusan Dalam Situasi Yang Kompleks.

Saaty, (1990), Multicriteria Decision Making: The Analytic Hierarchy process-Planing Prioroty Setting. Resource Allocation. McGraww-Hill, New York.

Thomas L. Saaty, (2010), Analytic Hierarchy Process. Prosiding: Jurnal. Vol. VI of the AHP Series, , 478 pp., RWS Publ., 2000 (revised). ISBN 0-9620317-6-3.

Wijono Djoko, (2015), Penggunaan Metode analytic Hierarchy Process Dalam Pengambilan Keputusan Penentuan Prioritas Program Kerja Dompet Dhuafa Yogyakarta.pdf

Ariyanto, (2014), Analisis Pengaruh Kompensasi dan Keputusan Kerja Terhadap Produktivitas Kerja Wiraniaga Suzuki PT Restu Mahkota Karya Jakarta.pdf
Jimbrong, G. (2010). Bab III (Sistem Pengukuran). Malang: Univ Negeri Malang.

Liana Setiono . (2006). AHP untuk Pengambilan Keputusan Dalam Situasi Yang Kompleks. pdf.

Musrifah, S. (2014). Statistik Parametrik dan Non Parametrik serta Uji Beda. Jember: Universitas Jember.

Nazir, M. (2008). Metode Penelitian. Jakarta: PT Ghakia Indonesia.

Riduwan. (2010). Metode dan Teknik Menyusun Tesis. Bandung: Alfabeta.

Rusydianan, A. S. (2013). Analytic Hierarchy Process : Pengantar Teori dan Aplikasi.

Schwab, K. (2016). The Fourth Industrial Revolution.

Siregar, S. (2014). Statistik Parametrik Untuk Penelitian Kualitatif. Jakarta: PT. Bumi Aksara. 